\title{
Preparing General Education Teacher To Meet The Challenges Of ADHD In The Classroom
}

Sandra B. Loughran, (E-mail: loughras@dowling.edu), Dowling College

\begin{abstract}
This article seeks to provide the general classroom teacher with better insight into the difficulties that ADHD behaviors create for children, their families, their teachers and their peers. It will also help teachers learn to recognize ADHD behavior early on and to inform them of some of the methods and techniques that can be helpful in managing ADHD, particularly in the classroom. However, children with ADHD aren't deliberately seeking attention: they're truly wired differently.
\end{abstract}

\section{INTRODUCTION}

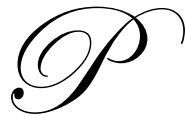

reparing General Education Teachers to Meet the Challenges of ADHD in the Classroom "At school they say I'm wired bad, or wired mad, or wired sad, or wired glad, depending on my mood and which teacher has ended up with me. But there is no doubt about it, I'm wired." (Gantos, 2000, p. 3). This is how Joey Pigza, a child with attention deficit hyperactivity disorder (ADHD), movingly describes his own experience.

There is a great deal of controversy and confusion surrounding ADHD. Many professionals in and out of the fields of education and psychology feel that the condition is highly overdiagnosed and overpathologized. Parents of children with ADHD will often deny its presence. New teachers sometimes have trouble distinguishing misbehavior from ADHD. At times, even experienced educators, faced with a child like Joey, who acts as if he's "off the wall," think that he's willfully misbehaving.

Today ADHD is the most commonly diagnosed behavioral disorder of childhood. Because an estimated 35\% of the school-aged population is diagnosed with ADHD (American Psychiatric Association, 2000), it's likely that in any classroom of 25 children, one or two children will present with the symptoms of ADHD. A general education teacher will almost certainly encounter ADHD in the classroom, a very challenging reality.

Before working with children with ADHD, teachers need to know its symptoms, and understand how these symptoms manifest themselves both in and outside of the classroom setting. It's also important that teachers distinguish between their responsibilities to the child and their responsibilities to the child's family. The good news is that a teacher can be a powerful source of support for both children with ADHD and their parents.

\section{WHAT IS ADHD?}

More children are referred to mental health professionals for ADHD than for any other behavioral disorder of children. The primary symptoms are developmentally inappropriate levels of inattention, impulsivity and hyperactivity, which are consistent over at least six months. The key words are "developmentally inappropriate." Most preschool children will generally show evidence of some of these behaviors on any given day; however, the child with ADHD presents these behaviors continuously and most likely early on in development, usually before seven years of age (American Psychiatric Association, 2000). 
Developmentally inappropriate levels of inattention mean that a child:

- $\quad$ shows significant deficits in sustained attention and effort

- $\quad$ is unable to remain vigilant or on task

- can't pay attention

- doesn't listen

- doesn't follow directions.

Developmentally inappropriate levels of impulsivity mean that a child:

- $\quad$ has difficulty inhibiting his/her behavior

- $\quad$ does everything rapidly but carelessly

- $\quad$ is a high risk-taker

- $\quad$ is unable to delay gratification

- $\quad$ has difficulty waiting his/her turn or sharing or cooperating with projects/tasks

- $\quad$ exhibits low tolerance for frustration while playing games

Developmentally inappropriate levels of hyperactivity mean that a child:

- $\quad$ cannot regulate his/her activity level

- $\quad$ exhibits excessive motor activity

- $\quad$ is always on the go

- $\quad$ can't sit still

- $\quad$ talks/climbs/ moves excessively

- $\quad$ highly accident prone

The effects of these symptoms can be devastating if left unchecked. Children with ADHD are at-risk for many reasons. For example, peer rejection is common. Because they are unable to inhibit actions, children with ADHD do not acquire social skills as easily or as naturally as other children do. They also are at risk for and can present co-existing symptoms of other behavioral disorders. When children are not helped to deal with the inattention, impulsivity and hyperactivity, they stand out in a crowd, especially in a classroom. Approximately $65 \%$ of the children referred for ADHD will also have Oppositional Defiant Disorder (ODD), which is defined as exhibiting hostile behavior to others, especially to parents. As many as $45 \%$ of them may eventually exhibit Conduct Disorder (CD) which is marked by highly aggressive behavior, particularly towards their peers (Barkley, 1995).

Children with ADHD tend to be very creative but at the same time academic underachievers. They struggle to stay on task and maintain attention to detail; they easily drift off and gradually fall behind. They have difficulty learning the basic math and reading skills. Between 20 and 30\% of these children also have learning disabilities (Barkley, 1995).

Not surprisingly, low self-esteem is very prevalent in children with ADHD. Teachers need to be on the lookout for signs of depression. With the negative attention that children with ADHD experience, not only in the classroom but also in the schoolyard, it is no wonder their self-concepts are often bruised. Some children may experience clinically significant depression warranting medication (Spencer, T. Biederman, J. Wilens, T., 1999).

\section{CAUSES OF ADHD}

Although the cause of ADHD isn't clear, there is strong evidence that biological factors are closely associated with the condition. Neurological studies of children with ADHD show less activity in the frontal lobe regions of the brain which involve behavioral inhibition, persistence of responding, resistance to distractions and control of one's activity level -- all the factors involved in ADHD - than in children without the condition. 
Russell Barkley, one of ADHD'S leading researchers and practitioners, believes that the condition is caused by a biological deficit in inhibiting behavior (Barkley, R. A., 1999). There is, in effect, a control switch in the brains of most children that controls their behavior to some degree. Children with ADHD appear to lack that control.

It is important that teachers understand this because it puts ADHD in a biological context. Children with ADHD doesn't exhibit outrageous, uncontrollable, and exasperating behavior because he/she wasn't given parameters. Indeed, their behavior isn't intentional, or at least not controllable, and usually is not directed at anyone. Teachers who understand that a child with ADHD truly cannot control behaviors can help that child to develop strategies to learn how to control himself.

\section{RECOGNIZING ADHD IN THE CLASSROOM}

Classroom teachers can best serve children and their parents by knowing how to detect ADHD, remembering that early detection is crucial. Although some children enter elementary schools already diagnosed, many are not. It's important to be proactive in getting help for children who present with symptoms of ADHD.

Good teaching involves creating good partnerships with parents. Teachers who have concerns about a child should first establish a positive relationship with the child's parents before discussing particular behaviors. Because teachers are not diagnosticians, it is best not to mention disorders to parents; instead, focus on the behaviors that are observed and describe how they are hindering the child's progress in school. Some parents have difficulty hearing that their child may have ADHD, and will evince resistance. For this reason, a classroom teacher may want to contact the person in the school who is responsible for making referrals (usually the guidance counselor, psychologist or social worker) before approaching parents directly. These specialists can become a support system for the teacher, and can also support the parents and child during the screening process and thereafter.

\section{HOW IS ADHD DIAGNOSED?}

Family physicians, developmental pediatricians, child neurologists, psychiatrists and psychologists are responsible for assessing, diagnosing and treating children with ADHD. Because there is often a hereditary component of ADHD, its assessment involves a complete developmental, environmental, and historical evaluation of the child. A medical history is also needed to rule out physical disorders that could be causing behaviors similar to those of ADHD. Depression or behavior resulting from poor childrearing practices also need to be ruled out.

Parent and teacher rating scales are used to assess the child's behavior in home and school settings. Because learning disabilities are common among children with ADHD, an assessment of academic achievement and a screening of general intelligence are also part of the protocol.

\section{TREATING ADHD}

There is no existing therapy that permanently corrects the underlying problem. ADHD is a chronic condition and, like any other chronic condition such as asthma and diabetes, it changes as a child grows. It is also like other chronic medical conditions in that the best means of coping with ADHD and minimizing its consequences is to make lifestyle changes and in some cases, to prescribe medication when necessary.

Among the treatments used for children with ADHD are medications, psychosocial treatments, dietary management, herbal and homeopathic treatments, biofeedback, meditation, and perceptual stimulation and training (National Institutes of Health Consensus Development Conference Statement, 2000). Long-term studies of children with ADHD (i.e. children who have been in treatment for more than one year) are lacking. Of the research available, studies show a positive effect when stimulants and psychosocial treatments are used over a short term (up to three months); however, the use of stimulant medication, in general, results in more positive behavioral changes than psychosocial treatments alone. To date, no studies show conclusive evidence as to the efficacy of other treatments. Clearly, more research is needed. 


\section{MEDICATION}

Not all children with ADHD need medication. It is not the protocol of first choice for children under five years of age. Medication, when appropriate, is recommended not alone but as one part of a broader treatment plan. Other interventions are needed to assist children with ADHD who have behavioral, social, and learning difficulties.

The most widely used medications to treat the symptoms of ADHD are stimulant drugs, among which are methylphenidate (Ritalin), dextroamphetamine (Dexedrine), and amphetamine (Adderall). In general, noisy, disruptive behavior diminishes with medication. Research has shown that these drugs have helped many children to sustain attention, reduce their impulses, and control rapid and irrelevant activity. Children on medication also appear more compliant and less aggressive. Sometimes antidepressants or antihistamines are also tried.

There has been controversy over whether immediate improvement in academic performance translates into greater gains in academic achievement over time (Barkley, 1998). Barkley concludes that stimulants produce significant improvement in academic accuracy and productivity but not necessarily in achievement.

When children improve after being given medication, the drug is usually credited for causing the change. But there is an alternate and perhaps more helpful and kindly view: "These changes are actually the child's own strengths and natural abilities coming out from behind a cloud. Giving credit to the medication can make the child feel incompetent. The medication only makes these changes possible. The child must supply the effort and ability. To help children feel good about themselves, parents and teachers need to praise the child, not the drug." (National Institute of Mental Health Publication No. 96-3572, Printed 1994, Reprinted 1996, p. 14).

Teachers play an important role letting parents and physicians know about changes in a child's behavior while on medication. Side effects can vary widely: no two children react to the same mediation in the same way. Some common side effects include temporary loss of appetite, lack of sleep, and mood swings.

\section{PSYCHOSOCIAL TREATMENT}

Some of the appropriate psycho-social treatments for children with ADHD are behavior management, behavior therapy, and cognitive-behavioral treatment including social skills training.

Behavior management (or contingency management) and behavior therapy use points, tokens, rewards, and time-out strategies that can be implemented in the classroom or at home and involve the parents, teachers or both.

Cognitive-behavioral treatment relies on self-monitoring, problem-solving and goal-directed strategies, verbal self-instruction and self-reinforcement. A self-monitoring technique that uses imaging is The Turtle Technique. When prompted by their teacher, children are asked to withdraw into their shells (come to a stop, pulling their arms and legs in like a turtle). They can do this on their own or the teacher can request that they respond to the "turtle" signal. In their turtle poses, children are taught to relax which helps them cope with emotional stressors (Robin et al., 1976).

Goal-directed strategies help children envision how they want things to turn out -- whether they're thinking of homework, a class project, or a social situation. Teachers can help children learn these skills by logically walking them through the steps necessary to accomplish a task.

All children can benefit from social skills training, but children with ADHD need it more because they often miss the hidden curriculum in social situations and cannot make inferences from body language. Teachers can teach social skills to the class as a whole: in this way, the child with ADHD doesn't feel singled out. Teachers can also break the skills into simple components. 


\section{SCHOOL AND THE MANAGEMENT OF ADHD}

Intelligence is rarely the problem for children with ADHD, who are often quite creative. However, as noted earlier, persistent academic problems may be attributed to a learning disability. Teachers should be aware of this correlation.

\section{ACADEMIC INTERVENTIONS}

In the revealing video, "How Difficult Can This Be?" Richard Lavoie (1989) distinguishes between fairness and equality, recognizing that no two children need the same things. Individualizing workloads is part of individualizing the curriculum. Some appropriate accommodations for children with ADHD include decreasing the workload where warranted according to individual needs. Teachers should stress quality, not quantity of work and performance.

Teachers should also consider adapting their instructional styles to reach out to children with ADHD. This may entail becoming creative when introducing and presenting new concepts, and assigning work that asks students to be active rather than passive. Not only will this capture the interest of the overactive child, but it may also engage the entire class. In addition, teachers need to encourage active participation and cooperative learning, and to monitor the pairing and grouping of children to ensure the optimum working environment for each child. Allowing for bodily movement frequently throughout the day can anticipate and dissipate many problems for the child with ADHD.

Proper management of a child with ADHD requires daily reflection. Teachers should observe each child keenly and keep a daily anecdotal record that includes positive as well as negative behaviors that arise. This can be a powerful document to share with parents. They want to know that the teacher truly knows and appreciates children's strengths as well as their weaknesses.

\section{MANAGEMENT STRATEGIES IN THE CLASSROOM}

While classroom management skills are a must for any teacher, there are some practical suggestions and general guidelines that are particularly pertinent and helpful when dealing with ADHD. Many of these refer to the need of the child with ADHD for more external structure to compensate for their relative inability to structure their internal experience. While all children need consistent limits and boundaries, the child with ADHD often needs these limits and boundaries to be very pronounced.

- Make frequent eye contact with the child. Encourage the child to look you in the eye when speaking, and to participate. Don't begin a class or story without each one's full attention. Remind, repeat, revisit the child with ADHD.

- $\quad$ Tape an extra set of classroom rules to the child's desk.

- $\quad$ Give frequent constructive feedback and encourage feedback from the child. Get to know how they perceive each situation.

- When the child is not performing or is misbehaving, state the problem and reset him/her in the right direction.

- Maintain priorities. Keep things as simple as possible. When teaching is meaningful and integrated with fun, all the children profit.

- $\quad$ Focus on the positives, not the negative. Notice what the child does well. Always be on the lookout for those sparkling moments and let him/her shine!

- $\quad$ Take action instead of talking. When you see situations developing, react immediately by going to that part of the room. Shouting across the room usually just exacerbates the situation by putting the child in trouble in the spotlight.

- Create and enforce immediate and appropriate consequences for bad behaviors or transgressions. Caution: Do not get emotional. Act as quickly and firmly as possible but with kindness. 
- $\quad$ Anticipate potential problems. Always have a plan when beginning a new project especially when trouble may be in store, such as during a field trip. Help children develop their own plan as to how to handle potential difficulties. Let them "own" it.

- $\quad$ Let children know what is expected, and let them know when they are living up to expectations.

- Give children a chance to show what they know. Reward and stroke them for participating in the process, not only when they give correct answers.

- $\quad$ Ask the child what would help him or her.

In addition to the above suggestions, the following guidelines are offered:

- Look at the whole child, not the behavior, or the handicaps. Really get to know the child as a unique and precious person. So many of these children have not been cherished, especially at school. They are a challenge to everyone in their lives including themselves. They need to know the people in their lives are on their team!

- Let the child with ADHD know that you know how difficult it is for him or her. Reorganize your expectations, don't lower them.

- Work with the child to instill as much success and positive self-attitude as possible. Don't personalize the problems of a child with ADHD, or let your emotions interfere with your goals or expectations for the child. A child with ADHD has real problems but you haven't created them.

- $\quad$ Educate yourself about ADHD. Build a support system. Find a specialist with whom you can consult, but do not diagnose.

- $\quad$ Practice forgiveness. Forgive the child for any transgressions or regression.

- $\quad$ Forgive yourself if and when you lose it. Children with ADHD become experts at knowing how to push buttons. Learn from these experiences.

- $\quad$ Provide a positive atmosphere.

- Have fun yourself.

- $\quad$ Engage children so that they can shine.

\section{CONCLUSION}

General education teachers must recognize that, sooner or later (most likely sooner) and on a continuing basis, they will be faced with ADHD in their classroom. It is important that they be prepared to deal with it on a daily basis. Teachers should be well informed on the nature and symptoms of the disorder and the resources and support structure within their school and community.

In the classroom focus on the child, not the problems brought on by the ADHD. Empathy with a child and the difficulties he or she is experiencing will go a long way in helping the situation.

The watchword is patience. Patience is a crucial factor in working with children with ADHD. Make that a mantra. Everyone involved needs to take one day at a time. Each day can be a new beginning and it is important to convey that kind of encouragement to a child with ADHD by saying, "Let's start all over today." Remember the power you have as the teacher. You can make all the difference in a child's day, not to mention his or her life!

\section{RESOURCES}

Children and Adults with Attention-Deficit/Hyperactivity Disorder (CHADD) is a non-profit organizationserving individuals with ADHD and their families. It is an open forum with over 200 local chapters in the U.S. CHADD offers information, education, advocacy, and support for individuals, parents, teachers, and professionals who work with individuals with ADHD. In addition to an informative website, CHADD also publishes a variety of printed materials to keep members and professionals current on research advances, medications and treatments affecting individuals with ADHD. Reif, S. F. (2005). How to reach and teach children with ADD/ADHD: Practical techniques, strategies, and interventions ( $2^{\text {nd }}$ ed.). San Francisco, CA:Jossey-Bass. 


\section{REFERENCES}

1. American Psychiatric Association (2000). Diagnostic and statistical manual of mental disorders (4 $4^{\text {th }}$ ed., rev.). Washington, DC: Author.

2. Barkley, R. A. (1999). Theories of attention deficit hyperactivity disorder. In H. C. Quay \& A. E. Hogan (Eds.), Handbook of disruptive behavior disorders (pp. 295-316). New York: Plenum.

3. Barkley, R. A. (1998). Attention-deficit/hyperactivity disorder. In E. J. Mash \& R. A. Barkley (Ed.), Treatment of childhood disorders (2nd. ed.). New York: Guilford.

4. Barkley, R.A. (1995). Taking charge of ADHD: The complete, authoritative guide for parents. New York: Guilford Press.

5. Gantos, J. (2000). Joey Pigza swallowed the key. New York: Harper Collins Publishers.

6. Lavoie, R. (n.d.). F.A.T. City, How Difficult Can This Be? Understanding Learning Disabilities . PBS Video, 1320 Braddock Place, Alexandria, Virginia 22314-1698.

7. National Institute of Mental Health Publication No. 96-3572, Printed 1994, Reprinted 1996, p. 14

8. National Institutes of Health Consensus Development Conference Statement. Diagnosis and treatment of attention-deficit/hyperactivity disorder (ADHD). Journal of the American Academy of Child and Adolescent Psychiatry, 2000; 39(2): 182-93. http://odp.od.nih.gov/consensus/cons/110/110_intro.htm

9. Peter Rosen Productions (Producers), \& Richard Lavoie (Director). (1989). How difficult can this be? The F.A.T. City workshop. Washington, DC: PBS Video.

10. Robin, A, Schneider, M., \& Dolnick, M. (1976). The turtle technique: An extended case study of self-control in the classroom. Psychology in the Schools, 13(4), 449-453.

11. Spencer, T. Biederman, J. Wilens, T. (1999). Attention-deficit/hyperactivity disorder and co morbidity. Pediatric Clinics of North America, 46(5), 915-27. 
NOTES 